Srios I

(1708-1826)

mins.s.

\title{
LXXIII. On flame
}

\section{J. Murray Esq.}

To cite this article: J. Murray Esq. (1816) LXXIII. On flame, Philosophical Magazine Series 1, 48:223, 360-362, DOI: $10.1080 / 14786441608637685$

To link to this article: http://dx.doi.org/10.1080/14786441608637685

$$
\text { 曲 Published online: } 27 \text { Jul } 2009 .
$$

Submit your article to this journal $匚$

Џll Article views: 3

Q View related articles $\asymp$ 
ore which is the subject of his experiments. Ores containing 30 per cent. and upwards of manganese, as in experiments 15 and 16, will fuse per se into glasses that will transmit light, and in thin fragments exhibit perfect transparency. This is not at all the case with ores of iron; a retention of 5 per cent. of iron will give an opaque bottle-green glass, and when it amounts to 10 per cent. the glass becomes black, shining, and metallic.

Recapitulation of the foregoing Experiments as to metallic Produce.

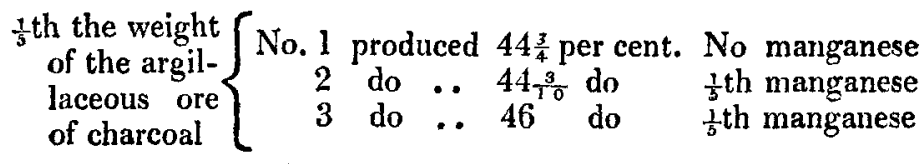

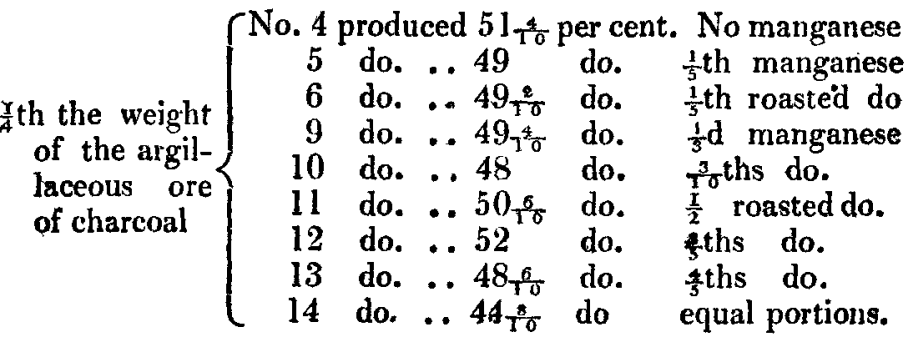

LXXIII. On Flame. By J. Murray, Esq.

To Mr. Tilloch.

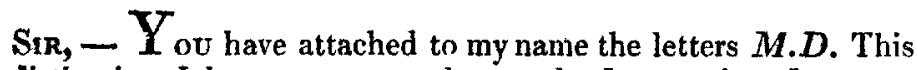
distinction I have not assumed, nor do I covet it. I request you will ectify the error, lest my more humble efforts in the cause of truth and science might in some instances, by my imperfect details, detract from the superior merits of Dr. John Murray of Edinburgh*. By a typographical error unhallowed is printed " hallowed."

In some instances, by introducing into the flame of a candle a spatula of ivory with gunpowder, I have withdrawn it in a moist state; and from the circumstance that fulminating silver inserted into the cone of flame has not been exploded for some seconds, - I deem it probable that the interior is filled up with aqueous matter, which emanates from the interior surface of the fame, as well as exterior. This medium of aqueous particles

- Identity of name led us into the mistake alluded to, and must plead our excuse,-EDrT. 
would account for the extinction of phosphorus, \&ie. when introduced.

In order to corroborate the solution I have proffered of the principle of security exhibited in the phænomena of Sir H. Davy's lamp, I may remark, that those persons who wear veils are sensible of a glow of heat exceeding the common temperature. Now in this instance the aqueous vapour which evolves in respiration fills up the open meshes of the veil, and from the interior surface the caloric is reflected back to the face. Either this is a correct solution, or it is accounted for by supposing that the calorific particles radiating in right lines, are interrupted in their rectilinear path by the fibres of the meshes, and being thus broken they are confined within the veil: surely the former speaks more the language of fact.

When the flame of a candle is viewed at a given distance through a good magnifying lens, it appears composed of a congeries of flbres wider at bottom, and approximating towards the summit, where they are bundled or tied together, being no doubt so many jets of aëriform inflammable matter expelled by heat.

Mr. Sym, in the last number of The Annals of Philosophy, says, that by pressing the apex of the flaming cone the temperature will be decreased. This may be naturally expected, and is easily explained. The top of the flame is as it were the focus where the fibres of flame are connected. By pressing upon the cone, this focus is destroyed. The fact of not being able to see objects through the upper part of the flame, while they can be readily discerned through the lower film, is proof positive that flame is transparent under certain forms-here it is attenuated.

The blue colour at the base of flame is worthy of particular notice. It is likely that the fibres of flame constituting this cone are so many capillary tubes into which the volatilized matter ascends by capillary attraction, and that oxygenous air circulates round the individual fibre. As they gradually approximate when they come towards the apex of the cone, there will be less and less space for the circulation of oxygen, and consequently the carbon will be more completely consumed toward the base than toward the middle or summit:- this will well illustrate Sir H. Davy's experiments on flame, which I read with considerable interest.

If an oxygenous medium obtained in the interior of the cone of flame, I see no reason why it should not be a solid column. By igniting alcohol, \&c. (without a wick) a hollow interior will be still found by pressing the apex.

No doubt in the phænomena of combustion and production 
of water and carbonic acid gas, the theory of definite proportions is beautifully preserved.

I feel now anxious to detail to you an experiment which may serve to benefit the cause of humanity-a cause to which I profess myself warmly attached. I came from the North on the top of the Glasgow mail, and had " to bide the pelting of the pitiless storm," the inside seats being pre-engaged from Carlisle. On the road we encountered a fierce snow-storm. The coachman and myself were nearly blinded by the uninternitting flakes, and the poor animals the horses were as painfully situated, and expressed as much. At the immediately succeeding stage I procured a piece of llack crape, and attached it to the lining of the hat, so that it hung vertically before the eye. This I found not only to prevent the snow from injuring the visual organ, by warding it off; but at the same time, by cutting off the adventitious rays, I was enabled to obtain a more distinct and better defined view than I else should have had. This provision also prevented the eye from being dazzled by the reflection of light from the surface of snow. Crape being an uneven surface, black lace work with fine open meshes might serve better. tion.

By mariners at sea, \&c. this may be held to merit atten-

$$
\begin{aligned}
& \text { I am with high respect, sir, } \\
& \text { Your obedient servant, } \\
& \text { Surry Institution, Novi 15, 1816. }
\end{aligned}
$$

J. MuRRay.

P.S. I was much gratified to find the miners in a colliery near Ayr, conducting their operations solely by the light exhibited by the fire-damp-formerly so terrible an engine of destruction.

J. M.

\section{On the Circle.}

\section{To Mr. Tilloch.}

Sir, - A Correspondent of Dr.'Thomson's (Annals of Philosophy, June 1816, p. 463), has attempted to demonstrate that no part of a eircle is a straight line. It may be supposed that this proposition is so evidently correct, as to render demonstration unnecessary. But however absurd the idea that curves are composed of small right-lines may appear, it is, either directly or indirectly, the foundation of most of the theorems relating to curves. A perfect circle can only be imaginary; there is no such thing in nature, and art is incapable of producing one. 